To calculate $\alpha$ for the first stage it has been assumed that the water initially contained 1 part in 5,000 of the heavy isotope ${ }^{4}$.

These results show that the separation occurs when the hydrogen ion itself is discharged. A possible explanation of the small degree of separation in the second stage is that $\mathrm{H}^{2}$ does not show over-voltage.

Clarendon Laboratory, C. H. Collie. Oxford. Sept. 13.

1 Iewis, J. Amer. Chem. Soc., 55, 1297 ; 1933

2 Lewis and Macdonald, $J$. Chem. Phys., 1, 341; 1933

8 "Gmelins Handbuch der anorganischen Chemie", 2 H., 209, 1927 - Bleakney and Gould, Phys. Rev., 44; 1933.

\section{A Second Whale Shark, Rhineodon typus, at the Galapagos Islands}

Is 1927, I recorded in Science the presence of the whale shark in the Galapagos Archipelago. This fish was seen on June 9, 1925, by Prof. W. K. Gregory and Mr. John Tee-Van of Dr. William Beebe's Arcturus Expedition. It was not captured but was seen under the stern of the ship and within $2-3 \mathrm{ft}$. of the surface. It soon sank, but not until it had been definitely recognised as a whale shark.

Included in my note were two other records of Rhineodon typus on the Pacific coast of South America ; a specimen taken at Callao, Peru, in 1873, and another in the Bay of Panama in 1884. The two Galapagos specimens bring the total to four for this region.

In the spring of 1933, while Mr. Vincent Astor of New York was cruising among the Galapagos Islands, a specimen of this huge fish was seen and captured in Elizabeth Bay, Albemarle Island, on March 11. It was swimming at the surface but sounded immediately when harpooned. For an hour and a half it towed the launch, weighing about three tons, at varying speeds (at times as great as six knots) and mostly in circles. Then it came to the surface and swam about sluggishly for about two and a half hours before it succumbed to repeated harpoonings and a number of shots from a heavy rifle. The original harpoon was so firmly driven into its thick hide that it never came out, although it was by the harpoon line that the boat was towed about. Comment was made at the time that the fish offered no resistance and put up no such fight as one would expect from a shark of its size.

The weight of this specimen could not be definitely determined, but Mr. Astor estimated it at about three tons. This was based on the fact that to get it aboard the yacht it was necessary to use the two davits by which the three-ton launch is lifted aboard. This is probably an under- rather than an overestimate.

This $23 \mathrm{ft}$. fish was a young specimen. The fish has been measured up to $45 \mathrm{ft}$. by Swinburne Ward in the Seychelles Islands, in the western Indian Ocean. H. M. Smith has estimated one at $60 \mathrm{ft}$. taken in a fish trap of that standard length in the Gulf of Siam. Several whale sharks have been taken in Florida waters and off Havana which measured $30-35 \mathrm{ft}$. 'over all'. A $\frac{1}{6}$ scale model of a $32-\mathrm{ft}$. specimen is on display in the Fish Hall of the American Museum of Natural History. The tail of the fish under consideration has been presented to the Museum by Mr. Astor and will probably be mounted and put on display later. A number of photographs of this specimen were taken by $\mathrm{Mr}$. Milton W. Holden. Copies of these have kindly been presented to our collection of such-the largest in the world.

For twenty years I have been recording occurrences of Rhineodon in various oceans, and I am pleased to add another to the list. For the data on which this note is based, I am under obligation to $\mathrm{Mr}$. Astor, who has added to the records of the whale shark in all the oceans the sixty-seventh specimen.

$$
\text { E. W. Gudger. }
$$

American Museum of Natural History, 77 th Street, New York. July 14 .

\section{Sickle-Fibres of the New Zealand Romney Lamb}

SICKLE-FIBRES have recently been the subject of communications to Nature by Prof. J. E. Duerden ${ }^{1}$ and Dr. S. G. Barker ${ }^{2}$. In a minute study of a fibre selected by Prof. Duerden as a typical sickle-fibre from a Blackface lamb, Dr. Barker found that along the sub-apical portion, between the sickle-shaped tip and the definitive fibre grown after birth, the area of cross-section was very little smaller, if at all, than that of the sickle region.

The New Zealand Romney is often accused of 'hairiness', that is, coarse medullation, but the breed as a whole is much less hairy than an avowedly hairy mountain type of sheep. I am not familiar with the Blackface birtheoat, but perhaps the coarseness of the sub-apical region of the representative fibre described by Dr. Barker is one expression of the hairiness of the breed. It is the purpose of this note to report that in the New Zealand Romney, though fibres with a coarser sub-apical region are plentiful, sickle-fibres abound in which the sickle-end is well medullated, while the sub-apical portion is free from medulla or very slightly medullated, and that such fibres are seen in the W.I.R.A. rotator to have every axis of a portion of the sickle-end greater than any axis whatever in the sub-apical region. This fact is of some theoretical interest to me, for I look upon this sub-apical thinning as one expression of the prenatal check, a phenorienon which appears to $m \theta^{3}$ not primitive, but specialised.

Now that Dr. Barker has told me about it, I detect within my thick sickle region the rotation of the axes of the cross-sectional ellipse. As a non-mathematician, I welcome Dr. Barker's treatment of this material. The hairs of mammals, growing only at the basal end, record the resultants of the changing forces at work in the follicle. These autographic records, pushed out in profusion from the skin of mammals, await the interpretation of any morphologist or physicist who may be able to decipher them. Casting my eye over a mob of sheep I have come to look upon each animal as an island universe, not of spheres, but of filaments, and from the mathematical study of these objects much illumination is to be expected.

Massey Agricultural College, F. W. DRY.

New Zealand.

Aug. 7.

1 Nature, 130, 736, Nov. 12, 1932.
NatURE, 131, 799, June 3, 1933.

3 J. Text. Inst., 24, T.161 ; 1933. 